\section{EMBRYRIDDLE Aeronautical University}

SCHOLARLY COMMONS
International Journal of Aviation, Aeronautics, and Aerospace

\title{
The Influence of Personality, Safety Attitudes, and Risk Perception of Pilots: A Modeling and Mediation Perspective
}

\author{
Scott R. Winter \\ Embry-Riddle Aeronautical University, scott.winter@mac.com \\ Joseph R. Keebler \\ Embry-Riddle Aeronautical University, joekeebler@gmail.com \\ Tracy L. Lamb \\ Embry-Riddle Aeronautical University, LAMBT4@my.erau.edu \\ Richard Simonson \\ Embry-Riddle Aeronautical University, simonsonr7@gmail.com \\ Robert Thomas \\ Embry-Riddle Aeronautical University, Bob.Thomas@erau.edu \\ Stephen Rice \\ Embry-Riddle Aeronautical University, scrice@outlook.com
}

Follow this and additional works at: https://commons.erau.edu/ijaaa

Part of the Other Psychology Commons

\section{Scholarly Commons Citation}

Winter, S. R., Keebler, J. R., Lamb, T. L., Simonson, R., Thomas, R., \& Rice, S. (2021). The Influence of Personality, Safety Attitudes, and Risk Perception of Pilots: A Modeling and Mediation Perspective. International Journal of Aviation, Aeronautics, and Aerospace, 8(2). https://doi.org/10.15394/ ijaaa.2021.1594

This Article is brought to you for free and open access by the Journals at Scholarly Commons. It has been accepted for inclusion in International Journal of Aviation, Aeronautics, and Aerospace by an authorized administrator of Scholarly Commons. For more information, please contact commons@erau.edu. 
Risk perception remains a concerning issue for pilots in aviation. Accurate perception of risk is a foundational aspect of making the right decisions within each pilot's skill level. The purpose of this study was to examine the influence of personality factors on pilot risk perception, along with the indirect relationship between personality and risk perception through safety attitudes. The data was assessed in two stages: first, creating the statistical model and second for validation of the model. The review of existing literature presents studies related to safety and risk-taking in aviation, personality and risk, and safety attitudes in aviation.

\section{Review of the Literature}

\section{Previous Studies of Safety and Risk-Taking in Aviation}

Ongoing research to understand the constructs of risk perception and risktaking behavior is essential to improving safety, especially in industries that are both complex and safety-critical. Sectors with characteristics of complex sociotechnical systems, such as aviation, have experienced a rich evolution in their approach to risk and accident prevention (Reason, 2016; Salmon et al., 2012). This evolution has moved from predominantly blaming the frontline operators - be they a driver, a pilot, or an air traffic controller-to awareness and recognition of an accident's organizational responsibility and a focus on the systems involved to support the operation (Newnam \& Goode, 2015).

Studies that focus on human factors constitute a significant part of the sociotechnical system and represent a significant contributing factor to aviation accidents - often between 70-83\% of all occurrences (AOPA, 2018; Oster et al., 2013; Reason, 1990; Woods, 2010). However, there is a growing requirement for a paradigm shift to examine the entire range of socio-technical and systemic reasons, to discover the deeper triggers for these occurrences, and to enable thinking towards total system resilience (Hollnagel et al., 2006; Levenson, 2004; Levenson, 2015; Salmon et al., 2012).

Studies have indicated a need for systems that support a pilot's understanding of risk concepts, including risk tolerance and perception, decisionmaking, goal setting, and strategy-selection may improve safety (Wiegmann \& Shappell, 2017; Winter et al., 2019). For example, having a flawed perception of one's abilities (e.g., overconfidence bias) has also been a significant predictor of pilots' risk-taking behavior (Drinkwater \& Molesworth, 2010; Orasanu et al., 2002). While working on improving total system resilience, the personal attributes involving a flawed judgment of risk (tolerance and behaviors) remain central focal points of accident prevention research (O'Hare, 1990; Molesworth et al., 2006).

Abundant literature supports the premise that various factors can influence a pilot's unique relationship with risk and that these factors are often shaped by the individual's experiences and traits (Buch \& Diehl, 1984; Causse et al., 2013). Studies examining pilots' attitudes combined with age and experience support aviation safety by building on the body of knowledge to understand the 'what' and 
'why' factors influencing a pilot's risk perceptions. Pilots' attitudes toward risk may, in part, relate to their amount of flight experience - usually measured in-flight hours - and their age (Cox \& Cox, 1991; Drinkwater \& Molesworth, 2010; Hunter, 2005; Knecht, 2013; Lund \& Rundmo, 2009; Molesworth \& Chang, 2009). A pilot's attitude has been shown to have the propensity for pilots to take risks. This finding is of particular significance when associated with an attitude of complacency. Explicitly focusing on complacency, Knecht (2013) indicated that pilots with between 500 and 1500 hours are the most vulnerable to hazardous attitudes such as complacency.

The pilot's aptitude or cognitive ability level has also been a factor in risk perception (Goeters et al., 2004), including pilots' cognitive abilities and age (Hardy $\&$ Parasuraman, 1997). Other studies investigated measuring risk-taking behaviors and perceptions as an outcome of an individual's determined intelligence and cognitive ability (Yates, 1990; Yates \& Stone, 1992). Ultimately, the cognitive ability of the pilot supports increased risk perception.

\section{Personality and Risk}

The relationship between personality type, risk tolerance, safety behaviors, and decisions in aviation has been examined since the 1950s when personality assessments started to be used for recruitment and selection of air traffic controllers, pilots, and other safety-critical personal (King et al., 2003; Taylor, 1952). It is essential to understand that personality variance is a continuum that can affect safety behaviors and risk-taking behaviors, operational decision-making, team performance, and even work ethics (King et al., 2003). Each individual's unique personality traits are developed from their exclusive personal experiences, which are interpreted and encoded as memories and mental frameworks influenced by previous experiences, relationships, bias, and heuristics (Goldberg, 1999). These mental frameworks and memories are stored in the long-term memory for future risk recognition, and judgment, decision making, and ultimately determine the individual's behavior and actions (Baiocco et al., 2008; Endsley \& Jones, 2012; Goldberg, 1999; McCrae \& Costa, 1990).

A reliable and generalizable taxonomy became popular in the 1980s, based on the foundational lexical research of many scientists who contributed to the refinement of today's 'Big Five' (Goldberg, 1999). The Big Five references five aspects of personality that individuals vary on; however, it does not categorize individuals into types (John \& Srivastava, 1999). While many metrics assess the Big Five, this study utilized the 44-item Big Five personality inventory (John \& Srivastava, 1999). The five personality traits as they relate to risk perception and behavior are described as follows: a) extroversion, b) openness, c) agreeableness, d) conscientiousness, and e) neuroticism. Below each trait is described in more detail. 
Extroversion. Individuals who score high on this personality trait generally enjoy being social. They are considerate of others' feelings and emotions (McCrae \& Costa, 1990). Studies have indicated that individuals who score higher on extroversion tend toward fast and spontaneous decision-making with actionorientated outcomes (Chauvin et al., 2007; Scott \& Bruce 1995). Quick and impulsive decision-makers often miss critical information and may not consider viable or safer alternatives (Riaz et al., 2012).

Openness. This personality trait aligns with individuals with a propensity to have higher levels of imagination, intuition, and intellect (Goldberg, 1992; McCrae \& Costa, 1990; Scott \& Bruce, 1995). Personality types that score high on openness are considered to have higher emotional stability and awareness (Miller $\&$ Ireland, 2005). However, they may make judgments and decisions on 'gut' instincts (Goldberg, 1992; McCrae \& Costa, 1990; Scott \& Bruce, 1995). Although studies have shown that this personality type tends to positively predict an intuitive and fast decision-making style, they use their intellect and creativity to rationalize (Riaz et al., 2012).

Agreeableness. Goldberg (1999) proposed the following facets for those individuals who score highly on agreeableness: sympathy, understanding, tenderness, morality, cooperation, warmth, and empathy. This type of personality tends to take a consultative approach to risk assessment and decision making (Riaz et al., 2012). This type of personality type will avoid confrontations, which in some circumstances may lead to agreeing with other more dominant personality types. However, agreeable personalities are generally less likely to engage in known risk (Chauvin et al., 2007; Riaz et al., 2012).

Conscientiousness. Individuals with this dominant personality type are described as organized, controlled, and thoughtful of their environment, making their judgments and decisions based on a methodical collection of all the information (Goldberg, 1999). Conscientious individuals have a strong sense of responsibility. They are competent planners who are cautious and have a conservative and rational approach to risk (Baiocco et al., 2008; Chauvin et al., 2007; McCrae \& Costa, 1990; Scott \& Bruce, 1995).

Neuroticism. Individuals who score highly on neuroticism are described as prone to anxiety, impulsivity, and self-consciousness. However, the latter may be masked by anger and deflection tactics, especially in stress (McCrae \& Costa, 1990). Studies have shown that this personality type often identifies with feelings of depression and frustration (McCrae \& Costa, 1990) and are frequently impulsive in their judgments and decision making (Batool, 2007; Shoemaker, 2010; Thunholm, 2004).

\section{Safety Attitudes in Aviation}

Ongoing research to understand the constructs of risk perception and risktaking behavior is essential to improving safety. Central to a pilot's operational 
decisions are their attitudes, including a) their introspective attitudes about themselves and their abilities (self-confidence), b) their extrinsic attitudes towards safety (safety orientation), and c) their 'relationship' with risk perception and management (risk orientation). Research has shown that a pilot's attitude does have a significant effect on their safety behaviors and their operational decisions, especially towards the perception and management of risk (Berlin et al., 1982; Hunter, 2005; Lubner et al., 2001; Platenius \& Wilde, 1989; Sanders \& Hoffman, 1976).

Safety Orientation. The FAA provides guidance to support and train pilots to develop a positive orientation around safety. This guidance includes training materials, courses, and manuals for pilots to learn to cultivate desirable safety attitudes, avoid hazardous attitudes, and embrace principles of safe aviation behaviors such as airmanship (Kern, 1997; Lamb, 2019). Pilots who indicate negative safety attitudes (e.g., hazardous thought patterns) have been directly linked to an overall lower safety orientation (Berlin et al., 1982; Hunter, 2005).

Risk Orientation. Aviation regulators like the FAA and flight training organizations aim to produce pilots who possess safety orientated attitudes and accurate perception and risk management. With the objective that pilots who embrace these safety attitudes will have a greater awareness and be able to proactively avoid accidents and incidents (Berlin et al., 1982; Hunter, 2005). A study by Ji et al. (2011) found that Chinese airline pilots, who possessed a lower tolerance for risk, were primarily influenced by operational safety behaviors indirectly through affecting hazardous attitudes. Hunter (2002) explained that the level of risk a pilot is willing to take is often related to its importance or goal.

The more 'pressure' a pilot feels to achieve the flight goal, the greater their risk tolerance. This 'pressure' to achieve flight objectives has been described as 'commercial pressure' and has resulted in many aviation accidents (Bearman et al., 2009; Shappell et al., 2006, 2007; von Thaden et al., 2006). Conversely, risk tolerance may be mediated by an aversion to a specific risk. For example, if a pilot is more fearful or dreads a possible outcome's perceived consequences, the tolerance for that risk will be reduced (Boholm, 1998; Mullet et al., 1993). As established, faulty judgments on aviation risk are a significant contributing factor to accidents. Pilots with the appropriate risk attitude and orientation are better equipped to operate safely, especially in times of commercial pressure and other stressors (Wickens et al., 1993).

Self Confidence. Despite improvements in technology and education, over 80 percent of all aviation accidents are related to human factors about faulty perceptions and risk management, poor attitudes relating to self-confidence (e.g., overconfidence bias), and safety orientations (FAA, 2009). Individuals who are either overconfident or lack confidence in their abilities, understanding, perceptions, and performance pose a severe threat to safe aviation operations 
(Drinkwater, \& Molesworth, 2010; Orasanu et al., 2002; Sulistyawati et al., 2011). The bipolar effect of confidence impairs risk perception, operational judgments, and situational awareness in many situations. It may also affect the other team members, resulting in overall poor performance (Flin et al., 2008; Moore \& Healy, 2008; Sulistyawatie et al., 2011).

\section{Existing Gaps in the Research and Current Study}

Studies have shown that the FAA's guidance material has helped improve the pilot's safety attitudes (Buch \& Diehl, 1984; Diehl, 1991). However, there is a literature gap about how or if personality relates to safety attitudes and risk perception and if safety attitudes mediate any relationship between personality and risk perception. Other gaps exist in the literature on the relationships between personality, safety attitudes, and risk perception, specifically in aviation, to improve operational safety. There are many dimensions to consider when trying to understand human risk-perception. Previous studies have focused on the many factors that govern risk evaluation and how they are linked to the perceiver's interpretation and judgment (Bouyer et al., 2001; Slovic, 1987). However, these prior studies focus on non-aviation hazards and risks in a non-aviation environment with non-aviation professionals. Lastly, there remain some literature gaps relating to pilot attitudes, the more comprehensive facets of each personality type, and how they influence risk-taking perceptions.

\section{Figure 1.}

The Latent Variable Model Depicting the Hypothesized Relationships in the Current Study

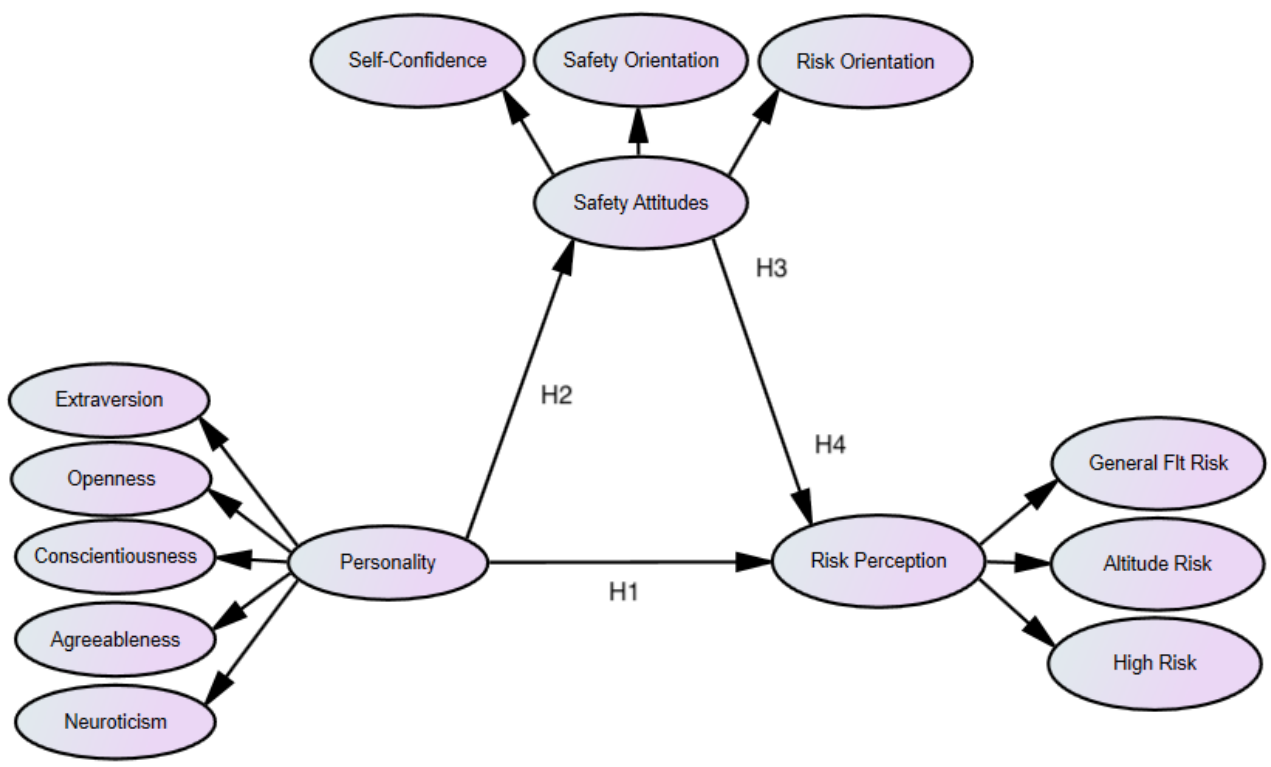




\section{Justification of Factor Selection and Hypotheses The Influence of Personality on Risk Perception}

The literature that does exist suggests that personality type may have a direct relationship with risk perception (Bouyer et al., 2001; Slovic, 1987). For example, previous studies indicate individuals who score higher on aggregate traits of conscientiousness and agreeableness tend to have a lower appetite for risktaking. Individuals who score higher on aggregate characteristics of extroversion and neuroticism tend towards fast decisions, spontaneous behaviors, and have a more increased need for risk (Bouyer et al., 2001; Slovic, 1987). Those individuals who indicate higher scores on neuroticism and extroversion tend towards spontaneous and fast decision making, reflecting less on consequences and more on actions to achieve flight goals (Batool, 2007; Shoemaker, 2010; Thunholm, 2004).

Hypothesis 1: Personality will have a direct and positive relationship with risk perception.

\section{The Influence of Personality on Safety Attitudes}

Attitudes and personalities are closely related constructs (Wilkening, 1973). Safety attitudes, including perspectives associated with high self-confidence inflight abilities and knowledge, safety orientation, and risk orientation, are indicated in the literature to be more prevalent in extroverted and neurotic personality types. Conversely, personality types that are more sensitive to others and methodical in their approach to risk may exhibit more conservative attitudes towards safety (Baiocco et al., 2008; Chauvin et al., 2007; McCrae \& Costa, 1990; Scott \& Bruce, 1995).

Hypothesis 2: Personality will have a direct and positive relationship with safety attitudes.

\section{Safety Attitudes influencing Risk Perception}

Safety attitudes do not have rigid boundaries, there is overlap or fuzzy logic between attitudes of self-confidence, safety orientation, and risk orientation, and these affect the risk perception of the individual decisions (Berlin et al., 1982; Hunter, 2005; Lubner et al., 2001; Platenius \& Wilde, 1989; Sanders \& Hoffman, 1976). Furthermore, it may be plausible that risk perception will be more effective by pilots who have a proactive safety attitude (Ji et al., 2011), including their attitudes and relationship with safety, risk, and individual assessment of their operational abilities.

Hypothesis 3: There will be a direct and positive relationship between safety attitudes and risk perception.

The Mediating Role of Safety Attitudes on Personality and Risk Perception

Attitudes are shaped by the individual's unique perceptions and experiences (Mullet et al., 1993; Teigen et al., 1988), and they may be related to personality. 
Therefore, it is plausible to consider that there will be a mediating effect of personality type on the individual and the perception of risk.

Hypothesis 4: Safety attitudes will meditate the relationship between personality and risk perception.

\section{Participants}

\section{Methods}

Participants were members of the Aircraft Owner's and Pilot's Association (AOPA) in the United States. AOPA's Air Safety Institute (ASI) assisted in deploying an email soliciting participation to approximately 10,000 randomly selected members. The email correspondence was sent to members in the middle of October 2019 and closed about four weeks later. A reminder email was sent to participants who had not responded to the questionnaire or read the initial email at the mid-point of the data collection period. Two thousand eight hundred and fiftyseven individuals completed the survey resulting in a response rate of approximately $28 \%$.

Table 1 provides a summary of demographic data for all participants. The overall average age of participants was $59.94(S D=13.03)$ years. Participants reported an average total number of flight hours as 4,278 $(S D=6,313, M d n=1,550)$ hours. Participants were randomly divided into separate samples for the initial model assessment in Stage 1 and model validation in Stage 2.

Stage 1 consisted of 1,429 participants. An initial screening of the data found 6 cases with excessive missing or incomplete data, which could not be remedied with imputation techniques, resulting in 1,423 usable cases. For the remaining items, the data appeared to be missing at random. Known value replacement was used to estimate missing values for reflective items (Hair et al., 2016). Stage 1 participants reported an average age of $59.85(S D=13.19)$ years, and they averaged 4,654 $(S D=6,753, M d n=1,600)$ total flight hours. The average number of commercial flight hours was 3,085 $(S D=6,282, M d n=0)$ hours.

Stage 2 consisted of 1,428 participants. An initial screening of the data found 6 cases with excessive missing or incomplete data, which could not be remedied with imputation techniques, resulting in 1,422 usable cases. For the remaining items, data appeared to be missing at random, and known value replacement was used to estimate missing values for reflective items (Hair et al., 2016). Stage 2 participants reported an average age of $60.03(S D=12.87)$ years, and they averaged 3,903 $(S D=5,874, M d n=1,500)$ total flight hours. The average number of commercial flight hours was 2,551 ( $S D=6,090, M d n=0)$ hours. 


\section{Table 1}

Summary of Descriptive and Demographic Statistics for all Participants

\begin{tabular}{|c|c|c|}
\hline Characteristics & Subcategories & Percentage $(\%)$ \\
\hline \multirow[t]{3}{*}{ Gender } & Male & 96 \\
\hline & Female & 3 \\
\hline & No Response & 1 \\
\hline \multirow[t]{5}{*}{ Ethnicity } & Caucasian & 95 \\
\hline & African descent & 0.5 \\
\hline & Hispanic descent & 2 \\
\hline & Asian descent & 0.5 \\
\hline & Other & 2 \\
\hline \multirow[t]{9}{*}{ Pilot Certificates } & Private Pilot & 56 \\
\hline & Instrument Rating & 49 \\
\hline & Commercial Pilot & 36 \\
\hline & Multi-Engine Rating & 34 \\
\hline & ATP & 23 \\
\hline & Flight Instructor & 26.5 \\
\hline & Instrument Instructor & 21 \\
\hline & Multi-Engine Instructor & 15 \\
\hline & Student Pilot & 3 \\
\hline \multirow[t]{6}{*}{ Primary Fly } & Part 91 Recreational & 69 \\
\hline & Part 91 Business & 12 \\
\hline & Part 121 & 8.5 \\
\hline & Part 135 & 4 \\
\hline & Part $91 \mathrm{~K}$ & 1 \\
\hline & Other & 5.5 \\
\hline
\end{tabular}

Note. Percentages rounded to nearest $1 / 2$ percent. Participants were able to select more than one pilot certificate/rating.

\section{Materials and Stimuli}

The instrument was created and hosted using Google ${ }^{\circledR}$ Forms. Participants were first presented with a digital consent form to which they had to agree and indicate they were above 18 years old before proceeding with the questionnaire. Following this, they were presented with the following instructions, "You will be presented with some scenarios, and you will then be asked some questions about each scenario. Following that, you will be asked some demographic questions. The data collection process is anonymous, and your responses will remain confidential. 
We expect that it will take you approximately 15 minutes to answer all the questions."

First, participants responded to the 44-item Big Five Personality inventory (John \& Srivastava, 1999). Participants were given the following information, "Here are a number of characteristics that may or may not apply to you. For example, do you agree that you are someone who likes to spend time with others? Please select for each statement the extent to which you disagree or agree with that statement." The lead-in sentence read, "I see myself as someone who..." which was followed by a randomized presentation of the 44-items anchored by a five-point scale from disagree strongly to agree strongly, with a neither agree nor disagree neutral option.

Next, participants responded to a modified Aviation Safety Attitudes Scale (ASAS) (Hunter, 1995). The original scale consisted of 27-items, but an earlier study by the research team found two items (items 21 and 25) did not properly load on the scale and were thus removed, resulting in a 25 -item scale. Participants read, "Please rate your level of disagreement or agreement with the following statements," and then were presented with the statements in a randomized order. Responses were recorded on a five-point scale, anchored from strongly disagree to strongly agree, with a neutral option of neither disagreeing nor agreeing.

Following this, participants responded to six questions asking how frequently they complete various safety activities, such as online courses, in-person seminars, and safety publications. Next, participants completed the 13-item Flight Risk Perception Scale (Winter et al., 2019). They read the following, "Please rate the level of risk present in the situation/scenario, if YOU were to experience the situation/scenario tomorrow," and then were presented with the randomized 13 statements. The responses were anchored on a nine-point scale from 1 (Low Risk) to 9 (High Risk).

These items concluded the related questions for the current study. As a result of the assessment being sent out by AOPA ASI, participants were asked to complete another questionnaire for a different study, provided demographics such as pilot certificates/ratings, total flight hours, age, gender, and ethnicity before being debriefed and dismissed. Participants did not receive compensation to complete the study.

\section{Design, Statistical Analysis, and Ethical Statement}

The study was conducted using a quantitative non-experimental predictive design. Structural equation modeling with mediation was implored as the data analysis technique due to latent variables and the direct and indirect effects between variables. The study was approved by the research university's Institutional Review Board (IRB) before conducting the research. All researchers held valid Collaborative Institute Training Initiative (CITI) certifications on human participants' proper treatment. This research complied with the American 
Psychological Association Code of Ethics and was approved by the Institutional Review Board at Embry-Riddle Aeronautical University. Informed consent was obtained from each participant.

\section{Exploratory Factor Analysis}

\section{Stage 1 - Results}

Since the three constructs (personality, safety attitudes, and risk perception) were each second-order factors, separate exploratory factor analysis was completed on each scale. For the Personality scale (John \& Srivastava, 1999), the data was initially assessed and found to meet the requirements to be factorizable. A maximum likelihood analysis using a Promax rotation was conducted on the scales used to measure their factor structure before conducting the confirmatory factor analysis. An initial review of the factors demonstrated low factor loadings, significant cross-loadings, and the scales' failure to load as anticipated. As a result, an iterative process was conducted to remove items with significant cross-loadings or low factor loadings. This process was completed an item at a time, and values of less than .5 were considered low loading. The resulting analysis produced a 5 -factor pattern matrix. For the final solution, the Kaiser-Meyer-Olkin (KMO) measure of sampling adequacy (MSA) was .858, which is considered 'meritorious' (Hair et al., 2016), and Bartlett's test of sphericity was statistically significant $(p<.001)$, thus suggesting the data were appropriate for factor analysis. The Cronbach's alpha values for the five scales ranged from .67 to .82, indicating acceptable and high reliability. The pattern matrix for the scales can be found in Appendix A.

For the Aviation Safety Attitudes scale (Hunter, 1995), the data was initially assessed and found to meet the requirements to be factorizable. A maximum likelihood analysis using a Promax rotation was conducted on the scales used to measure their factor structure before conducting the confirmatory factor analysis. An initial review of the factors demonstrated low factor loadings, significant crossloadings, and the scales' failure to load as anticipated. As a result, an iterative process was conducted to remove items with significant cross-loadings or low factor loadings. This process was completed an item at a time, and values of less than .5 were considered low loading. The resulting analysis produced a 2 -factor pattern matrix. The Risk Orientation factor did not hold and was thus removed, resulting in a second-order factor with two first-order constructs, self-confidence and safety orientation. For the final solution, the Kaiser-Meyer-Olkin (KMO) measure of sampling adequacy (MSA) was .799, which is considered 'middling' but just under the 'meritorious' criteria of 0.8 (Hair et al., 2016), and Bartlett's test of sphericity was statistically significant $(p<.001)$, thus suggesting the data were appropriate for factor analysis. The Cronbach's alpha values for the five scales ranged from .74 to .78 , indicating acceptable and high reliability. The pattern matrix for the scales can be found in Appendix A. 
For the Flight Risk Perception scale (Winter et al., 2019), the data was initially assessed and found to meet the requirements to be factorizable. A maximum likelihood analysis using a Promax rotation was conducted on the scales used to measure their factor structure before conducting the confirmatory factor analysis. An initial review of the factors demonstrated low factor loadings, significant cross-loadings, and the scales' failure to load as anticipated. As a result, an iterative process was conducted to remove items with significant cross-loadings or low factor loadings. This process was completed an item at a time, and values of less than .5 were considered low loading. The resulting analysis produced a 3 -factor pattern matrix. For the final solution, the Kaiser-Meyer-Olkin (KMO) measure of sampling adequacy (MSA) was .836, which is considered 'meritorious' (Hair et al., 2016), and Bartlett's test of sphericity was statistically significant $(p<.001)$, thus suggesting the data were appropriate for factor analysis. The Cronbach's alpha values for the five scales ranged from .63 to .82, indicating acceptable and moderate to high reliability. The pattern matrix for the scales can be found in Appendix A.

\section{Measurement Model Assessment}

Confirmatory factor analysis (CFA) was conducted to assess the measurement model with the latent constructs and observed variables used in the study. IBM $®$ SPSS $®$ AMOS 26 was used to test the CFA model. An initial screening of the data verified the statistical assumptions. An assessment of the skew found all values were within acceptable limits of $+/-3.2$, and all variables were within acceptable kurtosis ranges of +/- 7 (Byrne, 2016), except for RPS 1 (12.877) and RPS 4 (9.310). However, Brown (2006) suggests that kurtosis values of less than 10 are acceptable, and due to the exploratory nature of Stage 1, these variables were retained for data analysis.

The Stage 1 sample size of 1,423 eligible cases satisfies the minimum sampling requirements for CFA and SEM use. Next, an assessment of multivariate outliers was conducted based on Mahalanobis- $\mathrm{D}^{2}$ values greater than 100 . Twentyeight possible outliers were identified. The model fit statistics were compared without these outliers, and the values are shown in Table 2. Given the negligible difference in model fit and adequate sample size, these 28 cases were removed from the dataset for further analyses. 
Table 2

CFA Model Comparison Without and With Outliers

\begin{tabular}{lcc}
\hline Goodness-of-fit indices & $\begin{array}{c}\text { Sample without } \\
\text { outliers }\end{array}$ & $\begin{array}{c}\text { Sample with } \\
\text { outliers }\end{array}$ \\
\hline CFI & 0.865 & 0.868 \\
NFI & 0.830 & 0.833 \\
GFI & 0.882 & 0.885 \\
AGFI & 0.868 & 0.871 \\
RMSEA & 0.048 & 0.047 \\
CMIN/df & 4.155 & 4.105 \\
\hline
\end{tabular}

Following the initial data screening, model fit was assessed. Table 3 indicates the values of the initial model fit. Given the lack of adequate initial model fit, modification indices (MIs) were used through an iterative model respecification process one at a time to achieve an appropriate model (Byrne, 2016). The final CFA model demonstrated a good model fit, and the associated values are found in Table 3 as the re-specified model.

Table 3

Model Fit Statistics Along with the Initial and Re-specified Values

\begin{tabular}{|c|c|c|c|c|c|c|}
\hline Measure & Ideal & Adequate & Minimum & $\begin{array}{l}\text { Initial } \\
\text { Model }\end{array}$ & $\begin{array}{c}\text { Re-specified } \\
\text { Model }\end{array}$ & $\begin{array}{c}\text { Final Valid } \\
\text { Model }\end{array}$ \\
\hline \multicolumn{7}{|c|}{ Absolute Fit Measures } \\
\hline CMIN/DF & 1 & $<3$ & 5 & 4.155 & 3.172 & 3.239 \\
\hline SRMR & $<.06$ & $<.08$ & 0.10 & 0.0614 & 0.0547 & 0.0364 \\
\hline GFI & $>.95$ & $>.90$ & 0.90 & 0.882 & 0.933 & 0.961 \\
\hline RMSEA & $<.05$ & $<.08$ & 0.10 & 0.048 & 0.039 & 0.040 \\
\hline PCLOSE & & $>.05$ & & 0.993 & 1.000 & 1.000 \\
\hline \multicolumn{7}{|c|}{ Relative Fit Measures } \\
\hline NFI & $>.95$ & $>.90$ & 0.90 & 0.830 & 0.875 & 0.935 \\
\hline CFI & $>.95$ & $>.90$ & $>.80$ & 0.865 & 0.911 & 0.954 \\
\hline TLI & $>.95$ & $>.90$ & 0.90 & 0.856 & 0.904 & 0.947 \\
\hline AGFI & $>.90$ & $>.85$ & 0.80 & 0.868 & 0.912 & 0.951 \\
\hline
\end{tabular}

After completing the model fit assessment, it is necessary to evaluate the CFA model's construct validity and construct reliability. Construct validity was assessed through convergent and discriminant validity. Convergent validity was determined through an assessment of standardized factor loadings and average variance extracted (AVE). Hair et al. (2016) suggested that both standardized factor loadings and AVEs should be 0.5 or higher to demonstrate good convergent 
validity. Discriminant validity is assessed through maximum shared variance (MSV) less than AVE, the square root of AVE being higher than the inter-construct correlations, and correlations between factors being less than 0.7 (Hair et al., 2016). An initial assessment of construct validity and reliability identified problems, specifically with the first-order constructs of neuroticism, agreeableness, extraversion, safety orientation, and general flight risk. These constructs failed to demonstrate adequate AVE and reliabilities, and therefore, they were removed from the model.

Table 4 depicts that all standardized factor loadings were greater than 0.5 suggesting good convergent validity, except for openness, which was 0.48 but still considered adequate. All factors had AVEs greater than 0.5, suggesting good convergent validity of the CFA model. The final model fit numbers are depicted in Table 3 as the Final Valid Model, and Figure 2 shows the final valid CFA model.

Table 4

Convergent Validity, Discriminant Validity, and Construct Reliability

\begin{tabular}{|c|c|c|c|c|c|c|}
\hline $\begin{array}{l}\text { Second-Order } \\
\text { Factors }\end{array}$ & $\begin{array}{c}\text { First-Order } \\
\text { Factors }\end{array}$ & $\begin{array}{c}\text { Factor } \\
\text { Loadings }\end{array}$ & $\begin{array}{c}\text { Cronbach's } \\
\text { Alpha }\end{array}$ & $\begin{array}{l}\text { Construct } \\
\text { Reliability }\end{array}$ & AVE & MSV \\
\hline \multirow[t]{2}{*}{ Personality } & Openness & 0.48 & .787 & \multirow{2}{*}{.657} & \multirow{2}{*}{.510} & \multirow{2}{*}{.264} \\
\hline & Consci & 0.89 & .742 & & & \\
\hline \multirow[t]{2}{*}{ Flight Risk } & High Risk & 1.00 & .633 & \multirow{2}{*}{.820} & \multirow{2}{*}{.705} & \multirow{2}{*}{.051} \\
\hline & Altitude Risk & 0.66 & .825 & & & \\
\hline \multirow[t]{5}{*}{----} & Self-Confi & ---- & \multirow{5}{*}{.808} & \multirow{5}{*}{.813} & \multirow{5}{*}{.524} & \multirow{5}{*}{.264} \\
\hline & ASAS6 & 0.79 & & & & \\
\hline & ASAS8 & 0.78 & & & & \\
\hline & ASAS9 & 0.72 & & & & \\
\hline & ASAS13 & 0.58 & & & & \\
\hline
\end{tabular}

Not.: Consci $=$ Conscientious $;$ Self-Confi $=$ Self-Confidence .

Discriminant validity was assessed using the three parameters described above. Table 4 demonstrates that all MSV values are less than AVE values. Table 5 shows that the square root of AVE is higher than all other inter-construct correlations. Lastly, all correlations between factors were less than 0.6 , suggesting adequate discriminant validity. 


\section{Table 5}

Discriminant Validity

\begin{tabular}{lccc}
\hline & Personality & Risk Perception & Self-Confidence \\
\hline Personality & $\mathbf{0 . 7 1 4}$ & & \\
Risk Perception & 0.226 & $\mathbf{0 . 8 4 0}$ & \\
Self-Confidence & 0.513 & -0.064 & $\mathbf{0 . 7 2 4}$ \\
\hline
\end{tabular}

Note. Demonstrated by inter-construct correlations being less than the square root of AVE (diagonal in bold), and factor correlations are less than 0.6.

After completing the assessment of the data in the measurement model, the final CFA model is depicted in Figure 2. Table 6 illustrates the final constructs and items used in the model.

\section{Figure 2}

The Final CFA Model After Adjustments

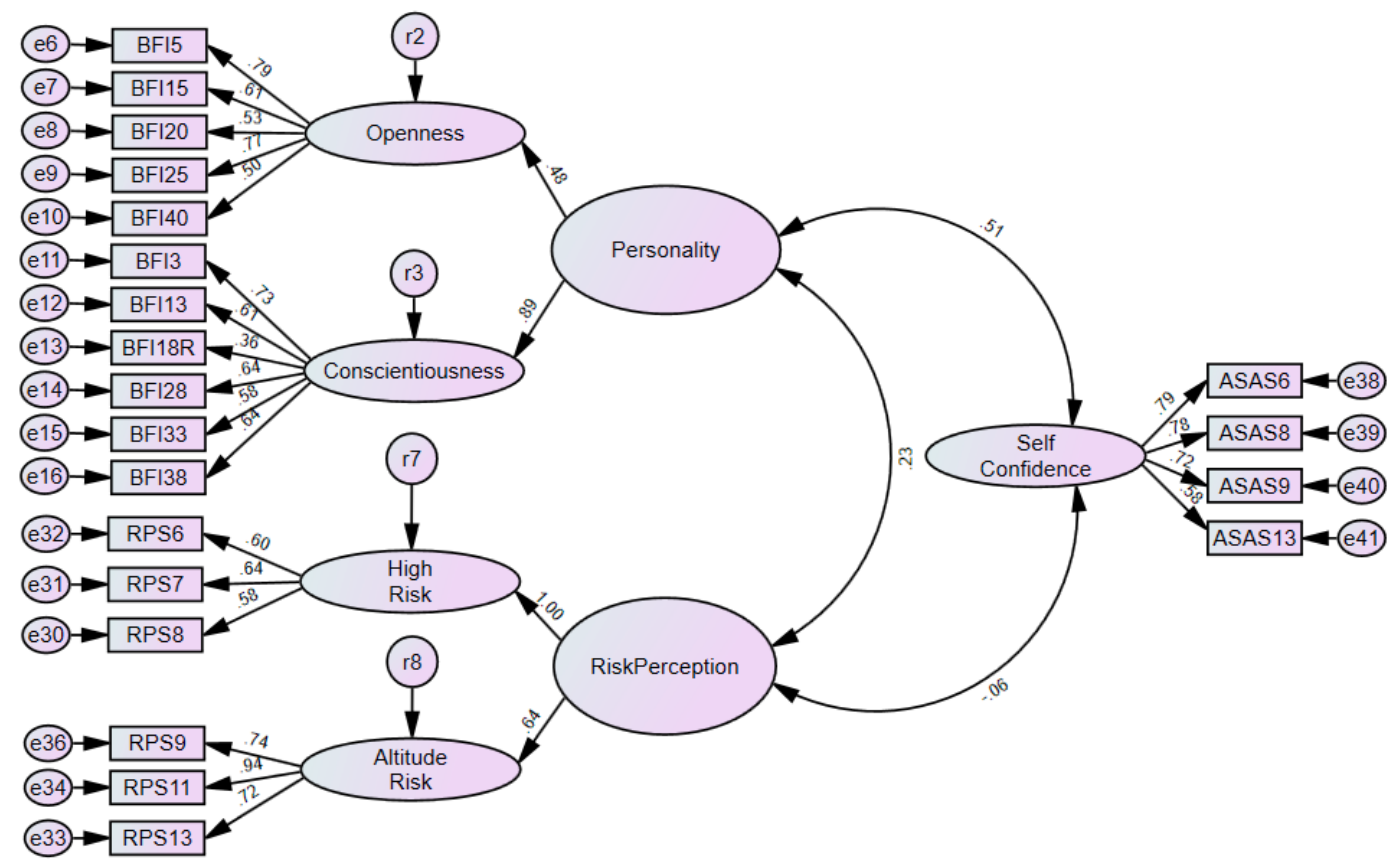

Note. Adjustments based on model fit and validity re-specifications. The standardized regression weights are depicted. 


\section{Table 6}

Constructs and Question Items

\begin{tabular}{|c|c|c|c|}
\hline Constructs & Items & $M$ & $S D$ \\
\hline \multirow{6}{*}{$\begin{array}{l}\text { Conscientious } \\
\text { (John \& } \\
\text { Srivastava, 1999) }\end{array}$} & BFI3: Does a thorough job. & 4.49 & 0.66 \\
\hline & BFI13: Is a reliable worker. & 4.76 & 0.49 \\
\hline & BFI18*: Tends to be disorganized. & 3.82 & 1.14 \\
\hline & BFI28: Perseveres until the task is finished. & 4.43 & 0.75 \\
\hline & BFI33: Does things efficiently. & 4.26 & 0.74 \\
\hline & BFI38: Makes plans and follows through. & 4.33 & 0.73 \\
\hline \multirow{5}{*}{$\begin{array}{l}\text { Openness } \\
\text { (John \& } \\
\text { Srivastava, 1999) }\end{array}$} & BFI5: Is original, comes up with new ideas. & 4.01 & 0.84 \\
\hline & BFI15: Is ingenious, a deep thinker. & 3.84 & 0.87 \\
\hline & BFI20: Has an active imagination. & 4.10 & 0.84 \\
\hline & BFI25: Is inventive. & 4.01 & 0.91 \\
\hline & BFI40: Likes to reflect, play with ideas. & 4.14 & 0.81 \\
\hline \multirow{4}{*}{$\begin{array}{l}\text { Self-Confidence } \\
\text { (Hunter, 1995) }\end{array}$} & ASAS6: I am a very capable pilot. & 4.06 & 0.72 \\
\hline & ASAS8: I am very skillful on controls. & 3.92 & 0.75 \\
\hline & ASAS9: I know aviation procedures very well. & 3.85 & 0.80 \\
\hline & ASAS13: I have a thorough knowledge of my aircraft. & 4.29 & 0.72 \\
\hline \multirow{2}{*}{$\begin{array}{l}\text { High Risk } \\
\text { (Winter, Truong, } \\
\text { \& Keebler, 2019) }\end{array}$} & $\begin{array}{l}\text { RSP6: Fly in clear air at } 6,500 \text { between two thunderstorms } \\
\text { about } 25 \text { miles apart. }\end{array}$ & 5.83 & 2.17 \\
\hline & $\begin{array}{l}\text { RPS7: Make a traffic pattern so that you end up turning for } \\
\text { final with about a } 45 \text {-degree bank. }\end{array}$ & 5.95 & 2.24 \\
\hline \multirow{4}{*}{$\begin{array}{l}\text { Altitude Risk } \\
\text { (Winter, Truong, } \\
\text { \& Keebler, 2019) }\end{array}$} & $\begin{array}{l}\text { RPS8: Make a two-hour cross-country flight with friends, } \\
\text { without checking your weight and balance. }\end{array}$ & 6.34 & 2.18 \\
\hline & $\begin{array}{l}\text { RPS9: Fly across a large lake or inlet at } 500 \text { feet above } \\
\text { ground level. }\end{array}$ & 7.04 & 2.06 \\
\hline & $\begin{array}{l}\text { RPS11: Fly across a large lake or inlet at } 1,500 \text { feet above } \\
\text { ground level. }\end{array}$ & 5.62 & 2.16 \\
\hline & $\begin{array}{l}\text { RPS13: Fly across a large lake or inlet at } 3,500 \text { feet above } \\
\text { ground level. }\end{array}$ & 4.29 & 2.06 \\
\hline
\end{tabular}

Note: $*$ indicates a reverse-scored item.

\section{Full Structural Model}

The full structural model was tested using structural equation modeling with IBM $®$ SPSS ${ }^{\circledR}$ AMOS 26. The initial model did meet the parameters for good model fit, and thus no model re-specifications were conducted by examining the modification indices (MIs) (Byrne, 2016). The model fit statistics for the full structural model are shown in Table 7, and the visual depiction of the full model is shown in Figure 3. 
Table 7

Model Fit Statistics for the Full Structural Model from Stage 1

\begin{tabular}{|c|c|c|c|c|}
\hline Measure & Ideal & Adequate & Minimum & $\begin{array}{l}\text { Initial } \\
\text { Model }\end{array}$ \\
\hline \multicolumn{4}{|c|}{ Absolute Fit Measures } & \\
\hline CMIN/DF & 1 & $<3$ & 5 & 3.239 \\
\hline SRMR & $<.06$ & $<.08$ & 0.10 & 0.0364 \\
\hline GFI & $>.95$ & $>.90$ & 0.90 & 0.961 \\
\hline RMSEA & $<.05$ & $<.08$ & 0.10 & 0.040 \\
\hline PCLOSE & & $>.05$ & & 1.000 \\
\hline \multicolumn{4}{|c|}{ Relative Fit Measures } & \\
\hline NFI & $>.95$ & $>.90$ & 0.90 & 0.935 \\
\hline CFI & $>.95$ & $>.90$ & $>.80$ & 0.954 \\
\hline TLI & $>.95$ & $>.90$ & 0.90 & 0.950 \\
\hline AGFI & $>.90$ & $>.85$ & 0.80 & 0.951 \\
\hline
\end{tabular}

Figure 3

The Final Full Structural Model from Stage 1

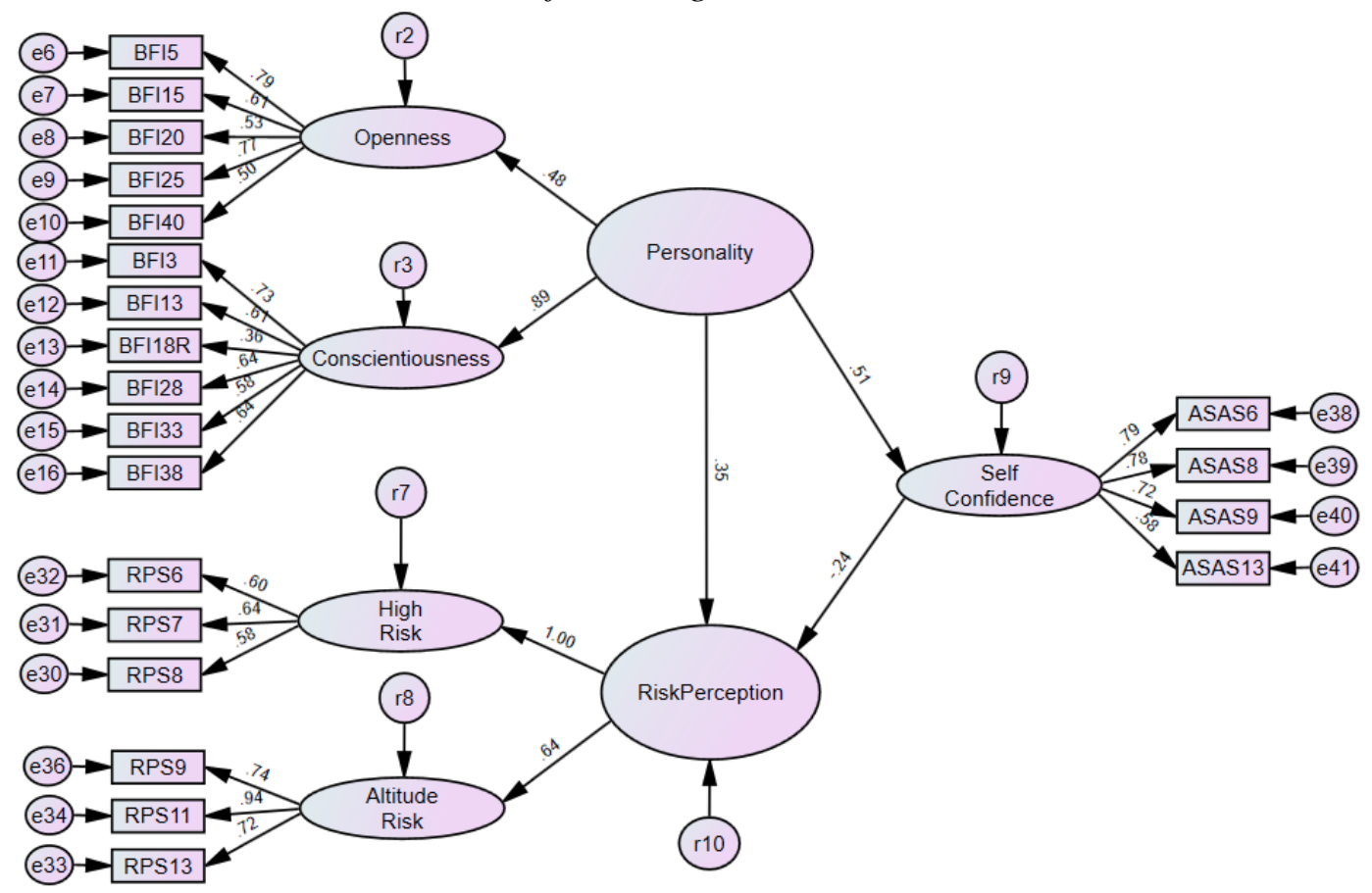

Note. Standardized regression weights are depicted. 
The model was found to explain approximately $26.4 \%$ of the variance in self-confidence and $9.5 \%$ of the risk perception variance. Three of the four initial hypotheses in the study were supported or partially supported. A summary of the direct relationships is found in Table 8a and the indirect relationship in Table 8b. Personality was shown to have a significant positive relationship with selfconfidence and risk perceptions. Self-confidence was a significant predictor of risk perception but negative. This relationship was opposite to the originally hypothesized direction, so technically this hypothesis is considered not supported.

The mediation analysis was completed using IBM $®$ SPSS $®$ AMOS 26 and 2,000 bootstrapped samples. The $95 \%$ confidence intervals $(\mathrm{CI})$ and $p$-values were assessed to determine if mediation was present. 95\% CI's that do not contain zero and $p$-values less than 0.05 indicate mediation. Self-confidence was found to mediate the relationship between personality and risk perception significantly. The inverse relationship suggests that as pilots' self-confidence increases, their perceptions of risk decrease. This decrease may result from either a more accurate understanding of risk as they gain more experience, or pilots may become overconfident in their abilities, resulting in lower risk perception scores.

\section{Table 8a}

Hypothesis Testing Results for Direct Relationships

\begin{tabular}{cccccccc}
\hline Hyp. & Relationship & $\boldsymbol{B}$ & $\boldsymbol{S E} \boldsymbol{B}$ & $\boldsymbol{\beta}$ & Critical Ratio & $\boldsymbol{p}$-value & Outcome \\
\hline $\mathrm{H}_{1}$ & Personality -> RP & 1.40 & 0.242 & 0.35 & 5.77 & $* * *$ & Sup. \\
$\mathrm{H}_{2}$ & Personality -> SA & 0.916 & 0.091 & 0.51 & 10.07 & $* * *$ & PS \\
$\mathrm{H}_{3}$ & Safety Attitudes -> RP & -0.545 & 0.166 & -0.24 & -4.70 & $* * *$ & NS \\
\hline
\end{tabular}

Note . RP = Risk Perception; $\mathrm{SA}=$ Safety Attitudes; Sup. = Supported; PS = Partially Supported; $\mathrm{NS}=$ Not Supported. While $\mathrm{H}_{3}$ is significant, it is in the opposite direction than originally hypothesized.

*** significant at the level of 0.01

\section{Table 8b}

Hypothesis Testing Results for the Mediation Hypotheses

\begin{tabular}{ccccccc}
\hline \multirow{2}{*}{ Hyp. } & \multirow{2}{*}{ Relationship } & \multirow{3}{*}{$\boldsymbol{\beta}$} & \multicolumn{2}{c}{ 95\% CI } & \multirow{2}{*}{$\boldsymbol{p}$-value } & \multirow{2}{*}{ Outcome } \\
\cline { 4 - 6 } & & Lower & Upper & & \\
\hline $\mathrm{H}_{4}$ & Personality $->$ SA (M) -> RP & -0.13 & -0.775 & -0.301 & 0.001 & PS \\
\hline
\end{tabular}

Not.: RP = Risk Perception; SA = Safety Attitudes; Sup. = Supported; PS = Partially Supported; NS = Not Supported

* significant at the level of 0.05 ;** significant at the level of 0.01 
Figure 4

Standardized Regression Coefficients

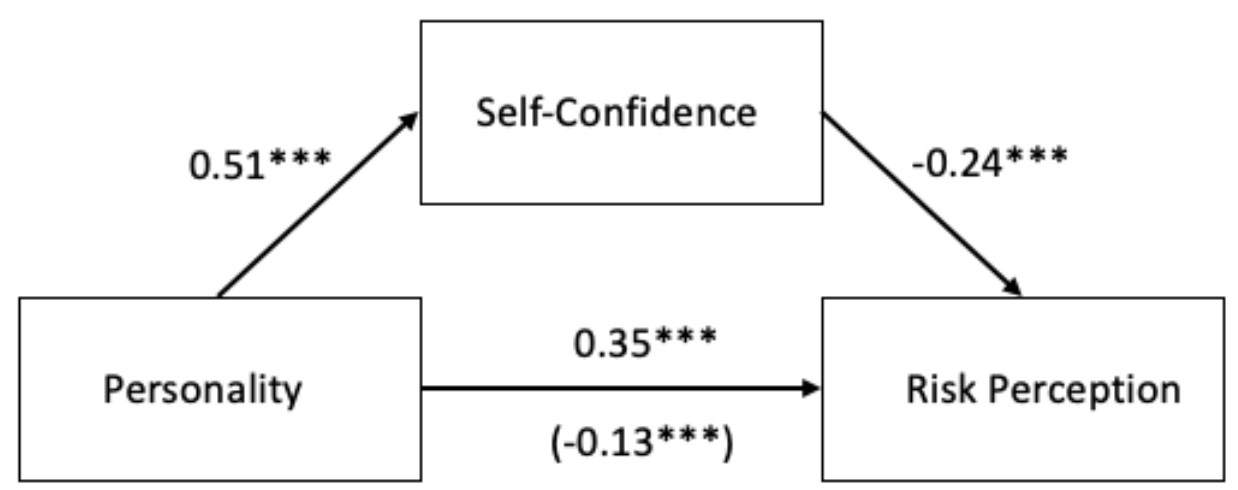

Note. The standardized regression coefficients for direct paths of the significant mediation model. Standardized regression coefficients for the indirect path are in parentheses.

$* * *$ indicates $p=$ or $<0.001$.

\section{Stage 1 - Discussion}

The results from Stage 1 present some interesting findings. Personality, specifically openness and conscientiousness, were significant predictors of risk perceptions in pilots. This finding suggests that, in general, as personality scores in pilots increase, they may be more likely to perceive higher risk levels given specific scenarios. Personality was also positively related to self-confidence, perhaps relating to the desire to do what is right. While in the opposite direction than hypothesized initially, self-confidence was negatively associated with risk perception suggesting that more confident pilots may be willing to take more chances and thus perceive a lower level of risk. Alternately, more self-confidence may be resulting in pilots more accurately assessing risk as they experience increases. Further research is necessary to understand this interesting relationship better.

Lastly, self-confidence significantly mediated the relationship between personality and risk perception, suggesting this relationship is, at least in part, explained by self-confidence. This indirect effect was negative, meaning that even for pilots with high personality ratings, self-confidence could result in a lesser perception of risk and potentially greater risk-taking. A pilot's self-confidence is likely to play a role in their assessment of risk, but it appears that high levels of self-confidence could lead to a reduction in risk perception by pilots. Caution needs to be observed to ensure that increases in self-confidence do not offset the flight's overall safety. 


\section{Stage 2 - Results}

Stage 2 was used to compare the model with a separate sample from Stage 1 to offer validation. Table 9 provides the model fit statistics for the final model from Stage 1 and the initial model run from Stage 2. The model fit statistics are exceptionally close, which suggests a valid model was found in Stage 1.

\section{Table 9}

Model Fit Statistics for the Stage 1 and Stage 2 Models

\begin{tabular}{|c|c|c|c|c|c|}
\hline Measure & Ideal & Adequate & Minimum & Stage 1 Model & Stage 2 Model \\
\hline \multicolumn{6}{|c|}{ Absolute Fit Measures } \\
\hline CMIN/DF & 1 & $<3$ & 5 & 3.239 & 3.615 \\
\hline SRMR & $<.06$ & $<.08$ & 0.10 & 0.0364 & 0.0383 \\
\hline GFI & $>.95$ & $>.90$ & 0.90 & 0.961 & 0.957 \\
\hline RMSEA & $<.05$ & $<.08$ & 0.10 & 0.040 & 0.043 \\
\hline PCLOSE & $>.05$ & & & 1.000 & 1.000 \\
\hline \multicolumn{6}{|c|}{ Relative Fit Measures } \\
\hline NFI & $>.95$ & $>.90$ & 0.90 & 0.935 & 0.930 \\
\hline CFI & $>.95$ & $>.90$ & $>.80$ & 0.954 & 0.948 \\
\hline TLI & $>.95$ & $>.90$ & 0.90 & 0.950 & 0.940 \\
\hline AGFI & $>.90$ & $>.85$ & 0.80 & 0.951 & 0.945 \\
\hline
\end{tabular}

Aside from assessing the model fit statistics, IBM ${ }^{\circledR}$ SPSS $®$ AMOS 26 can test for model invariance between multiple groups. In this study, Stage 1 and Stage 2 were treated as separate groups. There are two conventional techniques for assessing invariance between groups through either the chi-square difference test or the CFI differential (Byrne, 2016). Researchers have found the chi-square difference test to be overly stringent to assess invariance (Cudeck \& Browne, 1983; MacCallum et al., 1992). Therefore, the CFI differential was selected to test for model invariance (Cheung \& Rensvold, 2002). Cheung and Rensvold (2002) suggested a cutoff value of .01 between CFI for the various models when assessing for invariance between models. Table 10 provides a summary of the CFI difference assessment between the two stages. Due to all models having no greater CFI difference than .01, the two models are considered invariant, and thus, there are no differences in the model between the two groups. 
Table 10

Comparison of the Two Models by CFI Difference Assessment

\begin{tabular}{lcc}
\hline Model & CFI & $\Delta$ CFI \\
\hline Unconstrained & 0.951 & - \\
Measurement weights & 0.950 & .001 \\
Structural weights & 0.951 & .000 \\
Structural covariances & 0.951 & .000 \\
Structural residuals & 0.951 & .000 \\
Measurement residuals & 0.946 & .005 \\
\hline
\end{tabular}

\section{Stage 2 - Discussion}

The advantage of assessing validation is to determine the predictive aspects of the model. Without model validation on an independent sample, the original model is limited to being descriptive toward the data used to create it. Additionally, due to the model re-specification required in Stage 1, the validation sample in Stage 2 helps verify the final hypothesized structure found in Stage 1. By comparing model fit statistics with a secondary and independent sample and assessing model invariance between the two samples using CFI differential, the findings suggest that the current model is predictive of the relationships between personality factors, selfconfidence, and risk perceptions.

\section{General Discussion}

The relationships of a pilot's attitudes between facets of their personality, safety attitudes, and risk perceptions are not well understood within the aviation community. While research in various other domains has found links between these factors (c.f., Newnam \& Watson, 2011; Seibokaite \& Endriulaitiene, 2012; Wills et al., 2006, 2009; Wishart et al., 2017), these research initiatives have not been primarily initiated with a pilot-based demographic and cannot be reliably transferred to this field. Much of early pilot training focuses on tools such as the 'IMSAFE' mnemonic (illness, medication, stress, alcohol, fatigue, eating/emotion) as risk assessment tools, but these types of items do not offer great depth in understanding risk perception. Garnering a more robust understanding of these relationships may provide a multitude of advantages to the aviation community, including selection and training, accident avoidance, and higher perceived organizational safety (Kern, 1997; King et al., 2003; Taylor, 1952; Lamb, 2019; Wickens et al., 1993). To facilitate and quantify the understanding of these gaps in the literature, our study aimed to identify any relationship that may exist between personality via the Big Five model, safety attitudes through self-confidence, safety orientation, and risk orientation, and risk perceptions through general flight risk, altitude risk, and high-risk perceptions (Figure 1). Using a structural equation 
model (SEM) and split-sample cross-validation, we provide and validate a model that quantitatively describes these relationships.

The proposed and validated model provides a bridge in this literature gap by quantifying these three constructs' relationship. Through psychometric methods, reliability and validity testing deliver evidence of a validated relationship between the personality facets of conscientiousness and openness with self-confidence and risk perception. Specifically, we found that aspects of personality have a positive significant predictive value of risk perceptions. Further, by employing a SEM approach, we gained the capability to generate direct and indirect relationships between personality and self-confidence and their combined effects on risk perception. The resulting mediation analysis indicates that while facets of personality (i.e., conscientiousness and openness) do have a significant impact on a pilot's risk perceptions, personality also directly affects one's self-confidence, which also has a significant inverse effect on risk perception.

The study's exciting finding was the potentially offsetting mediating role of self-confidence between personality and risk perception. An inverse relationship was found with the mediator of self-confidence, suggesting that higher selfconfidence levels may lower risk perception ratings. Naturally, as a pilot gains more experience, their self-confidence would likely increase. However, if this selfconfidence would yield decreased risk perception and greater risk-taking, the overall safety level could be reduced. Further research is necessary to explore the possible offsetting aspect of self-confidence and its relationship to risk perceptions and risk-taking behaviors.

\section{Practical Applications}

Applications of this model are diverse and can include many implementations that consider a human pilot. For instance, personalities are intrinsic and based upon one's life experiences (Goldberg, 1999). As such, any amount of training or intervention cannot likely change this factor about a pilot. However, knowledge could be gained by a pilot understanding their personality breakdowns, and this awareness could influence their decision-making and risk perception skills. For example, if a pilot is made aware of low levels of conscientiousness, they may be more cautious when perceiving risk levels.

Additionally, our mediated model supports how some influence of personality on risk perceptions may be explained and modified due to selfconfidence. Of particular interest was the inverse impacts the mediator of selfconfidence had on risk perception, where increases in self-confidence resulted in lower perceptions of risk. Therefore, as pilots gain more self-confidence, they should identify if they are simply becoming more adept at assessing risk or taking part in riskier behaviors due to increased self-confidence. This finding is also relevant to flight instructors who may work with pilots on recurrent and continual training. In the training course, flight instructors could encourage a discussion with 
the pilot about how their perceptions toward risk and risk-taking behaviors are evolving as they gain more flight hours.

A further application of our model may provide a baseline to algorithmic pilot and co-pilot matching to adjust for possible safety or risk perception resonance (e.g., matching two pilots with similarly poor risk perception). Current pilot pairing algorithms rely on the availability and location of pilots, experience, and compatibility (Thiel, 2005; Yao et al., 2005). However, previously, with a fundamental understanding of how these factors influenced risk perception, algorithmically pairing aircrew to ensure compatible checks and balances of safety was not possible. A greater understanding of this information may be possible to implement pairing based on personality to create a low risk-tolerant flight crew in a validated form, although the logistics of this concept warrant further investigation of these relationships.

\section{Limitations}

A few limitations bound the current study. The data collection utilized responses of members of the Aircraft Owner's and Pilot's Association (AOPA) in the United States. While any pilot can be a member of AOPA, the sample of participants in the current study focuses on Part 91 general aviation (GA) operations and not as much on Part 121/135 commercial airline operations. The AOPA membership body skews towards an older male population with high standard deviations for total flight hours in both GA and commercial operations. The researchers relied on honest and accurate participants' responses to self-report their answers on the survey form. However, it is recognized that future research should expand on the current sample to verify the findings from this study and increase the generalizability.

The survey instrument's validity and reliability were assessed to ensure the data quality as part of the data analysis process, but certain items had to be revised. Further research to verify the validity of these instruments would seek to support the current study's findings and establish valid scales that could be used in many other research studies within the aviation field. Additionally, participating in activities such as seminars and online symposia, while a good practice, may not necessarily increase safety assessment or risk perception and further research is necessary to understand these relationships. Lastly, the low percentage of variance explained in risk perception suggests that more factors influence this variable. While the relationship between personality and self-confidence is interesting, along with the significant mediation of self-confidence, future research should examine what other factors influence pilots' risk perception.

\section{Conclusions}

The purpose of the current study was to assess personality factors' influence on risk perception and the indirect effects through safety attitudes. A sample of 
approximately 2,800 pilots was divided into two stages: model development and the other for model validation. Personality significantly influenced risk perception, while self-confidence was a significant mediator. The data indicated that high selfconfidence might result in reduced perceptions of levels of risk. Both the initial and validation models demonstrated a strong model fit.

\section{Acknowledgments}

The authors would like to thank the Aircraft Owner's and Pilot's Association's (AOPA) Air Safety Institute (ASI) for supporting this research project and assistance in data collection. 


\section{References}

Aircraft Owners and Pilots Association. (2018). 27th Joseph T. Nall Report: General aviation accidents in 2015. AOPA Air Safety Institute.

Baiocco, R., Laghi, F., \& D'Alessio, M. (2008). Decision making style among adolescents: Relationship with sensation seeking and locus of control. Journal of Adolescence, 20, 1-14.

Batool, S. (2007). Relationship between stress, self-efficacy and decision-making styles among university students (Unpublished M. Sc research report). Quaidi-Azam University, Islamabad: National Institute of Psychology.

Bearman, C., Paletz, S. B., Orasanu, J., \& Brooks, B. P. (2009). Organizational pressures and mitigating strategies in small commercial aviation: findings from Alaska. Aviation, Space, and Environmental Medicine, 80(12), 10551058.

Berlin, J. I., Gruber, E. V., Holmes, C. W., Jensen, P. K., Lau, J. R., \& Mills, J. W. (1982). Pilot judgment training and evaluation-Vol. 1 (Rep. No. DOT/FAA/CT-81/56-I). Federal Aviation Administration.

Brown, T. A. (2006). Confirmatory factor analysis for applied research. Guilford.

Bouyer, M., Bagdassarian, S., Chaabanne, S., \& Mullet, E. (2001). Personality correlates of risk perception. Risk Analysis, 21(3), 457-466.

Boholm, A. (1998). Comparative studies of risk perception: a review of twenty years of research. Journal of Risk Research, 1(2), 135-163.

Buch, G., \& Diehl, A. (1984). An investigation of the effectiveness of pilot judgment training. Human Factors, 26(5), 557-564.

Byrne, B. M. (2016). Structural equation modeling with AMOS: Basic concepts, applications, and programming (3rd ed). Routledge.

Causse, M., Dehais, F., Péran, P., Sabatini, U., \& Pastor, J. (2013). The effects of emotion on pilot decision-making: A neuroergonomic approach to aviation safety. Transportation Research Part C: Emerging Technologies, 33, 272281.

Chauvin, B., Hermand, D., \& Mullet, E. (2007). Risk perception and personality facets. Risk Analysis: An International Journal, 27(1), 171-185.

Cheung, G. W. \& Rensvold, R. B. (2002). Evaluating goodness-of-fit indexes for testing measurement invariance. Structural Equation Modeling, 10, 238262.

Cox, S., \& Cox, T. (1991). The structure of employee attitudes to safety: A European example. Work \& Stress, 5(2), 93-106.

Cudeck, R., \& Browne, M. W. (1983). Cross-validation of covariance structures. Multivariate Behavioral Research, 18, 147-167.

Diehl, A. (1991). The effectiveness of training programs for preventing 'aircrew error'. In International Symposium on Aviation Psychology, 6th, Columbus, OH (pp. 640-655). 
Drinkwater, J. L., \& Molesworth, B. R. (2010). Pilot see, pilot do: Examining the predictors of pilots' risk management behaviour. Safety Science, 48(10), 1445-1451.

Endsley, M. R., \& Jones, D. G. (2012). Designing for situation awareness: An approach to user-centered design. CRC.

Federal Aviation Administration. (2009). Pilot's handbook of aeronautical knowledge (FAA-H-8083-25a ed.). https://www.faa.gov/regulations_ policies/handbooks_manuals/aviation/phak/

Flin, R. H., O'Connor, P., \& Crichton, M. (2008). Safety at the sharp end: A guide to non-technical skills. Ashgate.

Goeters, K. M., Maschke, P., \& Eißfeldt, H. (2004). Ability requirements in core aviation professions: Job analysis of airline pilots and air traffic controllers. Aviation Psychology: Practice and Research, 99-119.

Goldberg, L. R. (1999). A broad-bandwidth, public-domain, personality inventory measuring the lower-level facets of several five-factor models. In I. Mervielde, I. Deary, F. De Fruyt, \& F. Ostendorf (Eds.), Personality Psychology in Europe, Vol. 7 (pp. 7-28). Tilburg, the Netherlands: Tilburg University Press.

Hair, J. F., Black, W. C., Babin, B. J., \& Anderson, R. E. (2016). Multivariate data analysis (8th ed). Prentice-Hall.

Hardy, D. J., \& Parasuraman, R. (1997). Cognition and flight performance in older pilots. Journal of Experimental Psychology: Applied, 3(4), 313-348.

Hollnagel, E., Woods, D. D., \& Leveson, N. (Eds.). (2006). Resilience engineering: Concepts and precepts. Ashgate.

Hunter, D. R. (1995). Airman research questionnaire: Methodology and overall results (Rep. No. DOT/FAA/AM-95/27). Federal Aviation Administration.

Hunter, D. R. (2002). Risk perception and risk tolerance in aircraft pilots (No. DOT/FAA/AM-02/17). Federal Aviation Administration.

Hunter, D. R. (2005). Measurement of hazardous attitudes among pilots. The International Journal of Aviation Psychology, 15(1), 23-43.

Ji, M., You, X., Lan, J., \& Yang, S. (2011). The impact of risk tolerance, risk perception and hazardous attitude on safety operation among airline pilots in China. Safety Science, 49(10), 1412-1420.

John, O. P., \& Srivastava, S. (1999). The big-five trait taxonomy: History, measurement, and theoretical perspectives. In L. A. Pervin \& O. P. John (Eds.), Handbook of personality: Theory and research (Vol. 2, pp. 102138). New York, New York: Guilford Press.

Kern, T. T. (1997). Redefining airmanship. McGraw Hill.

King, R. E., Retzlaff, P. D., Detwiler, C. A., Schroeder, D. J., \& Broach, D. (2003). Use of personality assessment measures in the selection of air 
traffic control specialists (No. DOT/FAA/AM-03/20). Federal Aviation Administration.

Knecht, W. R. (2013). The "killing zone" revisited: Serial nonlinearities predict general aviation accident rates from pilot total flight hours. Accident Analysis and Prevention, 60, 50-56. doi: 10.1016/j.aap.2013.08.012

Leveson, N. (2004). A new accident model for engineering safer systems. Safety Science, 42(4), 237-270.

Leveson, N. (2015). A systems approach to risk management through leading safety indicators. Reliability Engineering and System Safety, 136, 17-34. doi: 10.1016/j.ress.2014.10.008

Lamb, T. (2019). The changing face of airmanship and safety culture operating unmanned aircraft systems. In Unmanned Aerial Vehicles in Civilian Logistics and Supply Chain Management (pp. 243-265). IGI Global.

Lubner, M., Hunter, D., \& Struening, E. (2001). Reliability and validity of decision-making styles self-test. Focusing Attention on Aviation Safety.

Lund, I. O., \& Rundmo, T. (2009). Cross-cultural comparisons of traffic safety, risk perception, attitudes and behaviour. Safety Science, 47(4), 547-553.

MacCallum, R. C., Roznowski, M., \& Necowitz, L. B. (1992). Model modifications in covariance structure analysis: The problem of capitalization on chance. Psychological Bulletin, 111, 490-504.

McCrae, R. R, \& Costa, P. T. (1990). Personality in adulthood. Gilford.

Miller C. C., \& Ireland, R. D. (2005). Intuition in strategic decision making: Friend or foe in the fast-paced $21^{\text {st }}$ century? Academy of Management Perspectives, 19(1). https://doi.org/10.5465/ame.2005.15841948

Molesworth, B. R. C., \& Chang, B. (2009). Predicting pilots' risk-taking behavior through an implicit association test. Human Factors, 51(6), 845-857.

Molesworth, B., Wiggins, M. W., \& O'Hare, D. (2006). Improving pilots' risk assessment skills in low-flying operations: The role of feedback and experience. Accident Analysis and Prevention, 38, 954-960.

Moore, D. A., \& Healy, P. J. (2008). The trouble with overconfidence. Psychological Review, 115(2), 502.

Mullet, E., Duquesnoy, C., Raïff, P., Fahrasmane, R., \& Namur, E. (1993). The evaluative factor of risk perception. Journal of Applied Social Psychology, 23, 1594-1605.

Newnam, S., \& Goode, N. (2015). Do not blame the driver: A systems analysis of the causes of road freight crashes. Accident Analysis \& Prevention, 76, 141-151.

Newnam, S., \& Watson, B. (2011). Work-related driving safety in light vehicle fleets: A review of past research and the development of an intervention framework. Safety Science, 49(3), 369-381. http://dx.doi.org/10.1016/ j.ssci.2010.09.018 
O'Hare, D. (1990). Pilots' perception of risks and hazards in general aviation. Aviation, Space, and Environmental Medicine, 61, 599-603.

Orasanu, J., Fischer, U., \& Davison, J. (2002). Risk perception: A critical element of aviation safety. IFAC Proceedings Volumes, 35(1), 49-58.

Oster, C. V., Strong, J. S., \& Zom, C. K. (2013). Analyzing aviation safety: Problems, challenges, opportunities. Research in Transportation Economics, 43(1), 148-164.

Platenius, P. H., \& Wilde, G. J. (1989). Personal characteristics related to accident histories of Canadian pilots. Aviation, Space, and Environmental Medicine, 60(1), 42-45.

Reason, J. (1990). Human error. Cambridge University.

Reason, J. (2016). Managing the risks of organizational accidents. Routledge.

Riaz, M. N., Riaz, M. A., \& Batool, N. (2012). Personality types as predictors of decision -making styles. Journal of Behavioral Sciences, 22(2), 99-114.

Salmon, P. M., Cornelissen, M., \& Trotter, M. J. (2012). Systems-based accident analysis methods: A comparison of Accimap, HFACS, and STAMP. Safety Science, 50(4), 1158-1170.

Sanders, M. G., Hofmann, M. A., \& Neese, T. A. (1976). Cross-validation study of the personality aspects of involvement in pilot-error accidents. Aviation, Space, and Environmental Medicine,47, 177-179.

Scott, S. G., \& Bruce, R. A. (1995). Decision making style: The development and assessment of a new measure. Educational and Psychological Measurement, 55, 818-831.

Seibokaite, L., \& Endriulaitiene, A. (2012). The role of personality traits, work motivation and organizational safety climate in risky occupational performance of professional drivers. Baltic Journal of Management, 7(1), 103-118. http://dx.doi.org/10.1108/ 17465261211195892

Shappell, S. A., Detwiler, C. A., Holcomb, K. A., Hackworth, C. A., Boquet, A. J., \& Wiegmann, D. A. (2006). Human error and commercial aviation accidents: A comprehensive, fine-grained analysis using HFACS. Federal Aviation Administration.

Shappell, S., Detwiler, C., Holcomb, K., Hackworth, C., Boquet, A., \& Wiegmann, D. A. (2007). Human error and commercial aviation accidents: an analysis using the human factors analysis and classification system. Human Factors, 49(2), 227-242.

Slovic, P. (1987). Perception of risk. Science, 236, 280-285

Sulistyawati, K., Wickens, C. D., \& Chui, Y. P. (2011). Prediction in situation awareness: Confidence bias and underlying cognitive abilities. The International Journal of Aviation Psychology, 21(2), 153-174. 
Taylor, M. V. (1952). The development and validation of aptitude tests for the selection of personnel for positions in the field of air traffic control. American Institute for Research.

Teigen, K., Brun, W., \& Slovic, P. (1988). Societal risk as seen by a Norwegian public. Journal of Behavioral Decision Making, 1, 111-130.

Thiel, M. P. (2005). Team-oriented airline crew scheduling and rostering: Problem description, solution approaches, and decision support. Paderborn University, Paderborn, D. Sc. Thesis.

Thunholm, P. (2004). Decision making style: Habit, style or both? Personality and Individual Differences, 36(4), 931-944.

von Thaden, T. L., Wiegmann, D. A., \& Shappell, S. A. (2006). Organizational factors in commercial aviation accidents. The International Journal of Aviation Psychology, 16(3), 239-261.

Wickens, C. D., Stokes, A., Barnett, B., \& Hyman, F. (1993). The effects of stress on pilot judgment in a MIDIS simulator. In Time pressure and stress in human judgment and decision making (pp. 271-292). Springer.

Wishart, D., Somoray, K., \& Evenhuis, A. (2017). Thrill and adventure seeking in risky driving at work: The moderating role of safety climate. Journal of Safety Research, 63, 83-89.

Wiegmann, D. A., \& Shappell, S. A. (2017). A human error approach to aviation accident analysis: The human factors analysis and classification system. Routledge.

Wills, A. R., Watson, B., \& Biggs, H. C. (2006). Comparing safety climate factors as predictors of work-related driving behavior. Journal of Safety Research, 37(4), 375-383. http://dx.doi.org/10.1016/j.jsr.2006.05.008

Wills, A. R., Watson, B., \& Biggs, H. (2009). An exploratory investigation into safety climate and work-related driving. Work, 32(1), 81-94. http://dx.doi.org/10.3233/WOR-2009- 0818

Wilkening, H. E. (1973). The psychology almanac. Brooks.

Winter, S. R., Truong, D., \& Keebler, J. R. (2019). The flight risk perception scale (FRPS): A modified risk perception scale for measuring risk of pilots in aviation. The International Journal of Aviation Research, 11(1), 57-72.

Woods, D. D. (2010). Behind human error. Ashgate.

Yates, J. F. (1990). Judgement and decision making. Prentice Hall.

Yates, J. F., \& Stone, E. R. (1992). The risk constructs. In J. F. Yates (Ed.). Risk taking behavior (pp. 1-25). John Wiley.

Yao, Y., Zhao, W., Ergun, O., \& Johnson, E. (2005). Crew pairing and aircraft routing for on-demand aviation with time window. Available at SSRN 822265 . 


\section{Appendix A - Pattern Matrix from Exploratory Factor Analysis in Stage 1 for the Three Second-Order Scales}

Big Five Inventory (BFI) (John \& Srivastava, 1999)

\begin{tabular}{lccccc}
\hline & Extra & Open & Consci & Agree & Neurot \\
\hline Cronbach's Alpha & 0.825 & 0.787 & 0.742 & 0.668 & 0.720 \\
\hline BFI1 & 0.698 & & & & \\
BFI6* & 0.697 & & & & \\
BFI2* & 0.815 & & & & \\
BFI31* & 0.618 & & & & \\
BFI36 & 0.668 & & & & \\
BFI17 & & & & 0.673 & \\
BFI22 & & & & 0.552 & \\
BFI32 & & & & 0.592 & \\
BFI42 & & & & 0.557 & \\
BFI3 & & & 0.729 & & \\
BFI13 & & & 0.543 & & \\
BFI18* & & & 0.524 & & \\
BFI28 & & & 0.620 & & \\
BFI33 & & & 0.551 & & \\
BFI38 & & & 0.680 & & \\
BFI9* & & & & & 0.560 \\
BFI14 & & & & & 0.601 \\
BFI19 & & & & & \\
BFI39 & & 0.547 & & \\
BFI5 & & & & & \\
BFI15 & & & & \\
BFI20 & & & & \\
BFI25 & & & & \\
BFI40 & & & & \\
\hline
\end{tabular}

Note. Extraction Modes: Maximum Likelihood; Rotation Method: Promax with Kaiser Normalization; Rotation converged in 6 iterations; Extra $=$ Extraversion; Open $=$ Openness; Neurot $=$ Neuroticism; Agree $=$ Agreeableness; Consci $=$ Conscientious; $*$ indicates a reversescored item. 
Aviation Safety Attitudes Scale (Hunter, 1995)

\begin{tabular}{lcc}
\hline & Self-Confidence & Safety Orientation \\
\hline $\begin{array}{r}\text { Cronbach's } \\
\text { Alpha }\end{array}$ & 0.781 & 0.744 \\
\hline ASAS2 & 0.621 & \\
ASAS6 & 0.772 & \\
ASAS8 & 0.735 & \\
ASAS9 & 0.757 & \\
ASAS13 & 0.533 & \\
ASAS3 & & 0.839 \\
ASAS15 & & 0.744 \\
\hline
\end{tabular}

Note. Extraction Modes: Maximum Likelihood; Rotation Method: Promax with Kaiser Normalization; Rotation converged in 3 iterations.

Flight Risk Perception Scale (Winter, Truong, \& Keebler, 2019).

\begin{tabular}{lccc}
\hline & General Flight Risk & Altitude Risk & High Risk \\
\hline $\begin{array}{r}\text { Cronbach's } \\
\text { Alpha }\end{array}$ & 0.799 & 0.825 & 0.633 \\
\hline RPS1 & 0.698 & & \\
RPS2 & 0.745 & & \\
RPS3 & 0.566 & & \\
RPS4 & 0.737 & & \\
RPS5 & 0.569 & & 0.495 \\
RPS6 & & & 0.656 \\
RPS7 & & & 0.655 \\
RPS8 & & & 0.307 \\
RPS9 & & 0.609 & \\
RPS10 & & 0.471 & \\
RPS11 & & 0.923 & \\
RPS13 & & 0.826 & \\
\hline
\end{tabular}

Note. Extraction Modes: Maximum Likelihood; Rotation Method: Promax with Kaiser Normalization; Rotation converged in 4 iterations. 